\title{
LAS REFORMAS MONETARIAS DE 1931 Y 1932 EN MÉXICO: CRÍTICAS E INCOMPRENSIÓN
}

\section{MONETARY REFORMS OF 1931 AND 1932 IN MEXICO: CRITICISM AND LACK OF UNDERSTANDING}

\author{
Eduardo Turrent Díaz \\ Banco de México, ciudad de México, México, eturrentdiaz@outlook.com
}

Resumen. Durante mucho tiempo, el tema de las reformas monetarias en México de 1931 y 1932 estuvo olvidado. Recientemente ha resurgido el interés por ese asunto, pero desgraciadamente las publicaciones generadas dejan bastante que desear. El problema es la falta de comprensión sobre patrones monetarios y moneda en general. Dos fueron los problemas que dieron lugar a la reforma monetaria de 1931: a) la depreciación de la moneda de plata respecto a la de oro y b) de esta última (base del sistema monetario en vigor legalmente) respecto al dólar. El primer problema se resolvió exitosamente desmonetizando el oro. El segundo intentó resolverse, y se fracasó estrepitosamente, mediante la deflación monetaria buscando restaurar la paridad oficial que venía desde la reforma monetaria de 1905 equivalente a 2.006 pesos por dólar. El costoso error fue corregido finalmente por la administración hacendaria subsiguiente encabezada por Alberto Pani.

Palabras clave: reformas monetarias; deflación; desmonetización del oro; patrón oro.

Abstract. For a long time there was no interest among researchers on the topic of the monetary reforms Mexico enacted in 1931 and 1932. Recently the interest on that topic has reborn, but the papers written are even faultier. The main although not the only shortcoming in that literature, is the lack of understanding on how a monetary standard should work and, in general, about monetary theory. Two were the problems that lead to the monetary reform of 1931: a) depreciation of the silver coins in relation to gold coins, and $b$ ) devaluation of gold coins in relation to US dollar. The solution to the depreciation of silver coins was simple: demonetization of gold. However, the solution attempted in regards devaluation of the Mexican currency with respect US dollar resulted in failure. After reappointment in the Finance Ministry, Alberto Pani offered the final solution to the problem created.

Key words: monetary reforms; deflation: demonetization of gold; gold standard.

Fecha de recepción: 4 de marzo de 2012. Fecha de aceptación: 4 de junio de 2014.

Am. Lat. Hist. Econ., año 22, núm. 2, mayo-agosto, 2015, pp. 50-70 


\section{INTRODUCCIÓN}

$\mathrm{E}$ n los tratados de metodología se habla de que el trabajo del historiador -en cualquiera de sus especialidades, entre ellas la historia económica- se fundamenta en dos procesos, el heurístico y el hermenéutico. Por el segundo se entiende la búsqueda de fuentes -documentales, testimoniales, arquitectónicas, entre otras- para entender el pasado. El primero comprende los esfuerzos intelectuales y deductivos del especialista para entender qué ocurrió, cómo ocurrió, por qué ocurrió y de qué otras formas pudieron haber sucedido los acontecimientos. Precisamente en la heurística, o mejor dicho en la falta de comprensión del fenómeno que intenta estudiar, reside la falta irrescatable del trabajo de Luis Anaya (2012), "México no gana el oro que gasta: eso es la crisis. Polémicas sobre las reformas monetarias de 1931 y 1932". Esa falta de heurística -de entendimiento- es tan fundamental en ese ensayo, que el esfuerzo no encuentra salvación en algunos indudables logros hermenéuticos conseguidos por el autor. Por ejemplo, el importante hallazgo en relación con el Congreso Nacional de Economía que se celebró a inicios de 1931, en el cual pudieron existir guías para entender lo que sucedía en la economía de México a principios de los años treinta, y de esa comprensión derivar soluciones adecuadas de política económica. Sin embargo, desorientado al igual que Montes de Oca, Luis Anaya no acierta a extraer ningún indicio o guía útil de las deliberaciones que tuvieron lugar en ese evento. Así, el fruto encontrado no redituó alimento concreto y visible y terminó en esterilidad.

¿Qué sucedió entre 1917 y principios de 1932 en el orden monetario de México?, ¿cuáles fueron los problemas que se suscitaron con el patrón monetario que se reimplantó en 1918?, ¿ por qué la autoridad discurrió soluciones que resultaron incompletas, en el mejor de los casos, y en el peor, abiertamente fallidas?, ¿cómo fue el contexto externo en la materia de la moneda, que hizo las veces de escenografía, en el desenvolvimiento de los problemas monetarios que sufrió México en la época?, ¿qué participación tuvo la doctrina en las propuestas miopes que llevaron a la fallida reforma monetaria de 1931?, ¿ en qué consistieron las soluciones acertadas y exitosas que aplicó el sucesor de Montes de Oca en la Secretaría de Hacienda? Estos son los temas que deben estudiarse y esclarecerse. La finalidad es avanzar en la discusión sobre estos acontecimientos tan poco entendidos y de paso aclarar oraciones, puntos y comas con el pensamiento de Luis Anaya, estimable colega en lo personal.

La bibliografía que existe sobre las reformas monetarias entre 1931 y 1932 es escasa y, en general, de poco valor para dar respuesta satisfactoria a las finalidades enunciadas. Por un lado se tienen algunas referencias breves y con muy poca o nula intención analítica; algunos trabajos de una 
cobertura temática más amplia se citan en la lista de referencias incluida en el presente artículo. Es el caso de los tres ensayos de corte histórico incluidos en el volumen Cincuenta años de banca central (1976) a cargo, respectivamente, de Ernesto Fernández Hurtado, Antonio Carrillo Flores y Manuel Cavazos Lerma, además del libro de Virgil Bett (1957) y de los pasajes relativos en la exposición de motivos de la Ley Orgánica del Banco de México (1958, pp. 213-214, párrafo 8) de 1936 y de la cual fue ponente Miguel Palacios Macedo. En las obras, también incluidas en la lista de referencias, de Jaime Gurza (1941), Raúl Ortiz Mena (1942) y del propio Alberto J. Pani (1955), ya fueran de su autoría o con el sello de la Secretaría de Hacienda, como ministro de esta, el tratamiento del tema es más amplio aunque con la carencia de que sus autores no estaban suficientemente preparados en la materia de los patrones monetarios, sus finalidades y los prerrequisitos para su funcionamiento.

Por último, las líneas que siguen están inspiradas en lo fundamental en la cobertura de las reformas monetarias de 1931 y 1932 incluida en el libro de mi autoría Historia del Banco de México (1982, t. I). Infortunadamente, el artículo de Luis Anaya que motiva esta entrega no agrega nada a una mejor investigación y comprensión de estos temas. De ahí la necesidad de profundizar en su estudio.

\section{8: REIMPLANTACIÓN DEL PATRÓN ORO}

La situación monetaria prevaleciente durante la fase militar de la revolución mexicana llegó al caos a consecuencia de las cuantiosas emisiones de bilimbiques que hicieron las diversas facciones revolucionarias. Por su parte, el proyecto del billete infalsificable intentado por el régimen de Venustiano Carranza fracasó estrepitosamente. Con ese resultado, la posibilidad de restaurar en México las bases de un sistema monetario fundado en la emisión de billetes se volvió nula. En busca de una solución, el gobierno de Carranza contrató la asesoría de quien se consideraba entonces la máxima autoridad conocida en el mundo en el tema de la moneda. Se trataba del profesor Edwin Walter Kemmerer, conocido en las esferas académicas como Doctor Dinero (Money Doctor). Kemmerer viajó a México en 1917 y su visita fue todo un acontecimiento local, al cual los periódicos dieron una cobertura amplia. El resultado de esa asesoría fue un pequeño libro que se publicó en español y en inglés bajo el patrocinio de la presidencia de la república.

La recomendación de Kemmerer para México, contenida en la obra Sistema monetario de México (1917), fue la reimplantación del patrón oro. En su ensayo, Kemmerer ofrece una reflexión elaborada para justificar que 
el valor en oro de la moneda mexicana se mantuviera en el mismo nivel que se había establecido en 1905. En otras palabras, el tipo de cambio de la moneda nacional, necesariamente súper fijo e inamovible por tratarse de un esquema de talón oro, debería ser el mismo que se había determinado en ocasión de la reforma monetaria de 1905, por virtud de la cual el régimen porfirista había implantado en México un patrón monetario de esa naturaleza.

La paridad oficial era de 75 centigramos de oro por peso, lo que daba un tipo de cambio con la moneda estadunidense de 2.006 pesos mexicanos por dólar, dado el esquema de patrón oro vigente en Estados Unidos desde 1898. El problema de redondeo para este tipo de cambio oficial tiene su origen en el sistema métrico decimal, base del peso mexicano, y el sistema métrico inglés, base de la moneda de Estados Unidos; es decir, la equivalencia de la onza con el gramo de una onza por 28.35 gramos.

Era imposible, por el elevado precio que siempre ha tenido el llamado metal amarillo, que el cono monetario de un país que hubiese adoptado el patrón oro estuviese conformado en su totalidad con monedas acuñadas en ese metal. A manera de ejemplo, en Estados Unidos, Inglaterra, Alemania, Francia y otras naciones que habían implantado ese régimen de moneda, las especies de apoyo o morralla se acuñaban y emitían en cobre, bronce, zinc o algún otro metal o aleación de bajo valor. En el caso de México el problema era todavía más complicado, pues siempre habían circulado en el país monedas de plata. De hecho, la unidad del sistema monetario nacional siempre había sido una moneda troquelada en ese metal: el peso fuerte o simplemente peso de plata. Y el peso fuerte estaba acompañado en el cono por otras monedas fraccionarias de plata en las denominaciones de 50, 20 y 10 centavos. Por último, en el cono monetario legal sólo se incluían monedas de cobre en las denominaciones de cinco, dos y un centavo.

En su trabajo de asesoría para el gobierno de Carranza, Kemmerer prestó gran atención a la cuestión del precio relativo que debería acordarse entre las monedas de oro y de plata. La relación histórica de uno a 16 que había prevalecido por siglos se rompió de manera definitiva a partir de 1873, como consecuencia de la depreciación continua que sufrió el metal blanco contra el amarillo durante más de dos décadas. Por su parte, para la reforma monetaria de 1905 se había elegido la relación de 32 gramos de plata por uno de oro, pero Kemmerer temía que por la volatilidad del precio del metal blanco esa cotización no resultara sostenible. Finalmente, el precio relativo que se eligió para la reimplantación del patrón oro en México que se llevó a cabo en diciembre de 1918 fue el mismo de 1905.

¿Qué es un patrón monetario, o mejor dicho, qué se entendía por un patrón monetario hacía la segunda década del siglo XX? Un patrón mone- 
tario era un esquema que incluía dos componentes: una regla cambiaria y una regla monetaria. En el caso de la reimplantación del patrón oro llevada a cabo por México en 1918, la regla cambiaria fue la ya mencionada, donde un peso equivalía a 75 centigramos de oro puro. La regla monetaria sería que en el país únicamente circularían las monedas de oro de cuño nacional, contando esa circulación como especies de apoyo con las monedas de plata (de un peso y 50, 20 y diez centavos) y con las de cobre (cinco, dos y un centavo). Como estas dos últimas especies serian exclusivamente de apoyo o complementarias, su emisión debería responder estrictamente a una necesidad circulatoria legítima. Para asegurar esta última precondición, en la reforma de 1918 se especificó que las monedas de plata y de cobre únicamente se expedirían a cambio de moneda de oro. Asimismo, si la moneda de oro con la cual se habían adquirido las piezas de apoyo era mantenida en reserva por la autoridad emisora, la especie fraccionaria conservaría de forma permanente una garantía monetaria de 100 por ciento.

Así, para conformar una base suficientemente amplia de moneda metálica que sirviera de cimiento para la reimplantación del patrón oro, Luis Cabrera, secretario de Hacienda durante el mandato de Carranza, discurrió la incautación de las reservas metálicas que habían conservado en caja los bancos sobrevivientes a la revolución. "El dinero hay que tomarlo en donde se encuentre", comentó Cabrera enfáticamente para justificar tan draconiana medida (Manero, 1958). Otra fuente de moneda metálica provino del pago de aranceles por exportaciones e importaciones que se captaba en las aduanas. Una más estuvo conformada por la moneda metálica que había sido atesorada por particulares y que sus tenedores fueron sacando de escondites para reintegrarla a la circulación. Así, el cono monetario acordado por la reforma de diciembre de 1918 quedó integrado con las piezas según su respectiva fineza o ley -proporción de metal fino en relación con el peso total de la moneda (véase cuadro 1).

En el lapso de 1905 y 1918 se crearon varias monedas circulantes dignas de ser recordadas y que enriquecieron el cono monetario original que se consagró en la ley monetaria promovida por Limantour. Por orden de aparición, la moneda de oro de 20 pesos se creó en junio de 1917, aproximadamente quince meses antes de que se reimplantara en México el patrón oro. Asimismo, también cabe recordar el lanzamiento de otras dos monedas de oro en las raras denominaciones de $2.50 \mathrm{y}$ dos pesos en octubre de 1918 (Secretaría de Hacienda y Crédito Público, 1959, pp. 669-671). Estas monedas fueron creadas a raíz de que el precio de la plata experimentó una elevación muy marcada a lo largo de ese año. En respuesta, la autoridad tomó varias decisiones. Primero, redujo hasta en dos ocasiones la ley del peso fuerte de 0.930 a 0.800 y luego a 0.720 , e hizo también lo 
CUADRO 1. MÉXICO: CONO MONETARIO, DICIEMBRE DE 1918

\begin{tabular}{ll} 
Tipo de moneda & Ley o fineza de la moneda \\
Monedas de oro & \\
20 pesos & $(0.900)$ \\
10 pesos & $(0.900)$ \\
5 pesos & $(0.900)$ \\
2.50 pesos & $(0.900)$ \\
2 pesos & $(0.900)$ \\
Monedas de plata & \\
1 peso & $(0.800)$ \\
50 centavos & $(0.800)$ \\
20 centavos & $(0.800)$ \\
10 centavos & $(0.800)$ \\
Moneda de cobre & \\
5 centavos & s. d. \\
2 centavos & s. d. \\
1 centavo & s. d. \\
\hline
\end{tabular}

Fuente: elaboración propia con base en Secretaría de Hacienda y Crédito Público (1959, pp. 673-677).

propio con las piezas de 50 y 20 centavos al reducirles la fineza de 0.800 a 0.720 . Asimismo, a raíz de esa misma crisis, la moneda con denominación de diez centavos dejó de acuñarse en plata. Finalmente, por razones conmemorativas, aunque con importantes repercusiones monetarias, en 1921 se creó la moneda de oro en la denominación de 50 pesos. A la pieza se la llamó centenario porque fue creada para celebrar el primer siglo de la consumación de la independencia.

\section{ADULTERACIÓN E INVIABILIDAD DEL PATRÓN ORO}

El funcionamiento e incluso la viabilidad de un esquema de patrón oro dependía del cumplimiento de tres requisitos. El primero de ellos, según se ha dicho líneas atrás, era que la moneda de apoyo se emitiera y circulara únicamente en complemento de la especie fundamental, que era la de oro. En el caso del patrón oro adoptado por México, quizá cabría agregar la precondición de que la relación de valor entre el oro y la plata nunca fuera menor a 32. En caso de una apreciación del metal blanco por arriba de 
ese nivel operaría la ley de Gresham y las piezas troqueladas en ese metal serían retiradas de la circulación para ser atesoradas. El tercero y último requisito fundamental era la flexibilidad de los precios internos. El tema requiere aclaración. En razón de que el tipo de cambio se encontraba totalmente fijo, el mecanismo de ajuste para la balanza de pagos dependía de que se cumpliera plenamente con dicha condición. Sin embargo, lo que sucedió en la realidad en muchos países y no sólo en México, es que la flexibilidad de los precios no se satisfacía igualmente hacia el alza que hacia la baja. La asimetría se materializaba así, en que hacia la contracción los precios resultaban rígidos (sticky) y se resistían a descender.

En suma, el mecanismo de ajuste supuesto en el patrón oro era asimétrico o incompleto. Funcionaba eficazmente en caso de expansión, pero se atoraba cuando el proceso de ajuste requería de la contracción monetaria para inducir por esa vía un descenso de los precios y, anteriormente, un fortalecimiento de los términos de intercambio del país en cuestión.

En cuanto a México, el hecho fundamental para el patrón oro que se reimplantó en 1918, fue que los requisitos primero y tercero explicados arriba se fueron incumpliendo en forma creciente en el transcurso de la década de los veinte. El primero, relativo a la escasez relativa de la moneda de apoyo y la existencia de una garantía en la forma de una reserva monetaria suficiente para su respaldo, empezó a socavarse en el lapso que medió entre 1922 y 1926. El fenómeno que dio lugar a ese socavamiento fueron las acuñaciones masivas de moneda de plata que la Secretaría de Hacienda llevó a cabo durante dicho periodo. Estas acuñaciones de moneda de plata - principalmente de la especie de un peso-fueron iniciadas por el secretario de Hacienda Adolfo de la Huerta y continuadas temporalmente por su gran antagonista, crítico y sucesor, Alberto J. Pani. ¿’Por qué Pani, siendo un severo crítico de la gestión hacendaria de Adolfo de la Huerta, repitió y reincidió en el máximo pecado monetario cometido por el sonorense? Es algo que no ha podido aclararse.

Las acuñaciones masivas de moneda de plata tuvieron una motivación presupuestal. Después de la burbuja alcista del precio de la plata ocurrida durante 1918 y 1919, la década de los veinte fue un periodo de precios muy bajos en el mercado internacional para el metal blanco. En esa forma, por cada peso de plata que acuñaba la Secretaría de Hacienda, tenía que gastar aproximadamente la mitad del valor facial en la adquisición del metal fino incorporado en las piezas. Es decir, por cada peso de plata que acuñaba y expedía la Secretaría de Hacienda, podía echarse al bolsillo, por la vía de la apropiación de señoreaje, aproximadamente 50 centavos.

Los cálculos específicos fueron los siguientes: en 1921 el señoreaje ascendió en promedio a casi 51 centavos y, respectivamente, en los años de 1922, 1923, 1924, 1925 y 1926 el promedio anual de ese concepto se ubicó 
en $46.6,48.6,46.7,46$ y 50.4 centavos. El círculo se cierra recordando que en todos esos años las acuñaciones de plata fueron muy cuantiosas.

En suma, las acuñaciones de moneda de plata que inició De la Huerta durante el cuatrienio de Álvaro Obregón (1920-1924) y que continuó Pani a principios de la presidencia de Plutarco Elías Calles, fueron literalmente masivas. Los datos de esa acuñación se muestran en el cuadro 2, del cual pueden extraerse varias conclusiones. En primer lugar, que varios años de acuñaciones masivas de moneda de plata arrojan un total agregado muy grande para esa época de 223200000 pesos. Quizá por el tipo de régimen monetario en vigor y por el incipiente avance de la estadística económica en el país, no se cuenta con una serie sobre el volumen de moneda en circulación para esos años. Con todo, la cantidad de moneda de plata que se acuñó debió ser muy grande si se considera que en 1910 la masa monetaria total se estimó en 40000000 de pesos. En esa misma línea de argumentación, un cálculo sobre ese agregado realizado hacia 1927 por Enrique Martínez Sobral y citado por Raúl Ortiz Mena (1942) arrojaba un total de 365000000 de pesos, del cual casi 67\% correspondía a moneda de plata. ¿Especie monetaria de apoyo? La moneda de plata se había convertido en la principal especie circulante en México. Ello, en abierta contraposición con el esquema de patrón oro oficialmente en vigor.

\section{Problemas MONETARIOS: 1925-1930}

El exceso de monedas de plata en circulación, y también la depreciación del metal blanco, dio lugar a que en el intercambio de esas piezas, respecto a las de oro, se aplicase un descuento o castigo. Este castigo o descuento empezó a aparecer en el mercado desde octubre de 1922, cuando ascendió a casi $2.7 \%$. Y ese proceso de depreciación continuó hacia adelante con algunas alzas y bajas. En promedio, dicho descuento se ubicó en 1.65\% para $1923,1.61 \%$ para 1924 y $1.56 \%$ para 1925 , hasta que su magnitud empezó a elevarse en forma acelerada a partir de julio de 1926. Así, durante los últimos cuatro meses de ese último año, dicho descuento se ubicó en promedio en $5.5 \%$, cerrando en 8.95 por ciento.

A principios de 1927 el ministro Pani renunció a la cartera de Hacienda y su sucesor, el contador público Luis Montes de Oca, preocupado por el desplome de la moneda de plata, decidió en febrero de ese año expedir un decreto prohibiendo las acuñaciones en ese metal (Ortiz, 1942, anexo 9). Montes de Oca obró en el sentido correcto al tomar dicha medida, pero su aplicación ya nada podía hacer para resolver el problema de fondo. Ese problema era el exceso de moneda de plata dentro de la oferta monetaria total. $\mathrm{Si}$ acaso la medida tan sólo podría conseguir que el 
CUADRO 2. MÉXICO: ACUÑACIONES DE MONEDA DE PLATA, 1920-1927 (CIFRAS EN MILLONES DE PESOS)

\begin{tabular}{lccr}
\hline Año & 20 centavos & 50 centavos & Un peso \\
& & & \\
1920 & 3.7 & 27.2 & 8.8 \\
1921 & 6.2 & 21.9 & 5.5 \\
1922 & s. d. & s. d. & 33.6 \\
1923 & s. d. & s. d. & 35.3 \\
1924 & s. d. & s. d. & 33.1 \\
1925 & 1.5 & 3.3 & 9.2 \\
1926 & s. d. & s. d. & 28.8 \\
1927 & s. d. & s. d. & 5.1 \\
Totales & 11.4 & 52.4 & 159.4 \\
\hline
\end{tabular}

Fuente: elaborado con base en Douglas y Gómez (1997). Catálogo de monedas y onzas mexicanas del siglo $X X$ (pp. 23, 30 y 36). México: (s. e.).

fenómeno no se agudizara. Así, durante los años siguientes subsistió el descuento de la moneda de plata respecto a la de oro, habiéndose registrado en el transcurso dos crisis de gran intensidad. La primera ocurrió en el lapso de enero a junio de 1928, en el cual el mencionado descuento se ubicó, en promedio, apenas por debajo de $10 \%$. La segunda y más grave crisis se inició durante el otoño de 1930 y se intensificó a lo largo del primer semestre de 1931 con un promedio de 17.5\%, para cerrar en junio y julio con la cotización de $26 \%$. Fue a lo largo de esos meses de crisis cuando bajo el impulso del ministro Montes de Oca (Ortiz, 1942) empezó a gestarse la reforma monetaria de 1931.

Igual o mayor preocupación despertó en el ministro Montes de Oca la devaluación que empezó a sufrir la moneda mexicana de oro respecto al dólar de Estados Unidos durante su gestión hacendaria. El fenómeno se produjo por un efecto de oferta y demanda y por una causa de naturaleza jurídica con implicaciones monetarias: la prohibición legal que existía desde 1924, y que nunca fue removida, de exportar oro amonedado o en barras (Secretaría de Hacienda y Crédito Público, 1926, pp. 15 y 32).

Es de creerse lo que en su momento expresó el escritor Antonio Espinosa de los Monteros (1931) en el sentido de que los pagos que hizo México entre 1926 y 1928 al Comité Internacional de Banqueros por concepto de la Enmienda Pani -donde se renegoció la deuda externa hasta por 22000000 de dólares- pusieron mucha presión en el mercado de cambios. En el orden comercial, cabe también destacar la caída vertigino- 
sa que sufrieron durante esos años, y hasta principios de la década siguiente, los ingresos por exportación de petróleo y por otros conceptos como las ventas de plata al exterior.

El resultado de la disminución de la oferta de dólares y de otras divisas hacia el país fue la depreciación o devaluación cambiaria que sufrió la moneda de oro mexicana respecto al dólar. La depreciación respecto a la cotización oficial de 2.006 se registró por vez primera en octubre de 1926 (2.08) y continuó elevándose hasta julio del año siguiente (2.15). Como se muestra en el cuadro 3, la tendencia hacia la devaluación bajó a mediados de 1927 y mediados de 1929, pero a lo largo de todo 1930 se intensificó hasta llegar a 2.19 al cierre de ese año. En términos monetarios, o bien del funcionamiento del sistema monetario en vigor (patrón oro), esa devaluación se pudo haber evitado al permitir la exportación libre de oro para que los pagos en esa especie hicieran las veces de variable de ajuste, a fin de evitar que el desequilibrio de la balanza de pagos se reflejara en el tipo de cambio.

\section{El BANCO DE MÉXiCo y El PATRÓN ORO}

El establecimiento del Banco de México implicó una ampliación para el esquema del patrón oro que México había adoptado desde 1905 y que había reimplantado en 1918. Según la ley orgánica de esa institución, que se publicó en agosto de 1925, al Banco de México correspondería ejercer en exclusiva la facultad de emitir billetes de acuerdo con lo dispuesto en el artículo 28 de la Constitución. En el orden circulatorio, el billete del Banco de México se vendría a sumar al cono monetario con el que contaba el país y que se integraba con las monedas de oro y plata, además de las piezas fraccionarias que se acuñaban en cobre, níquel y otros metales no preciosos.

En términos de la ley constitutiva del Banco de México, el instituto central únicamente podría emitir billetes por tres canales: a cambio de oro amonedado o en barras, de giros pagaderos sobre el exterior (es decir, también oro) y mediante las operaciones de redescuento que practicara con sus bancos asociados (Secretaría de Hacienda y Crédito Público, 1957, p. 87, art. 1, fracción IV). Legalmente, el billete del Banco de México sería de aceptación voluntaria para el público. Asimismo y de manera muy importante, el único canal por el cual la emisión de billete podría incrementar la circulación monetaria sería el del redescuento. Por los otros dos conductos previstos en la ley, la emisión simplemente equivaldría a una sustitución en la circulación de monedas de oro por billetes.

Las autoridades -gobierno de Plutarco Elías Calles- tenían grandes expectativas en que el billete del Banco de México pudiera penetrar en la circulación de una manera gradual pero continua. Desgraciadamente no 


\section{CUADRO 3. MÉXICO: DEVALUACIÓN DEL PESO ORO}

(PESOS POR DÓLAR)

\begin{tabular}{cccc}
\hline Años & Paridad oficial & $\begin{array}{c}\text { Cotización } \\
\text { (promedio anual) }\end{array}$ & $\begin{array}{c}\text { Diferencial } \\
\text { (en centavos) }\end{array}$ \\
1927 & 2.006 & 2.1100 & \\
1928 & 2.006 & 2.0800 & 10.40 \\
1929 & 2.006 & 2.0700 & 7.40 \\
1930 & 2.006 & 2.1200 & 6.40 \\
1931 & 2.006 & 2.4100 & 11.40 \\
\hline
\end{tabular}

Fuente: elaborado con base en Ortiz (1942, anexo 8).

ocurrió de esa manera. Dos factores fueron los causantes de esa decepción monetaria. El primero y muy importante fue que hubo una gran renuencia del público para aceptar los billetes del Banco de México. El recuerdo de los bilimbiques revolucionarios estaba aún fresco en la memoria de la población, y el billete del Banco de México no lograba penetrar ni mantenerse en la circulación. Lo que ocurría en términos prácticos era que los vendedores se negaban a recibir en pago el billete o, habiéndolo recibido, acudían a la brevedad a una sucursal del Banco de México a canjear las piezas de papel por moneda metálica. El otro gran impedimento provino de la renuencia de los bancos comerciales a asociarse al Banco de México.

Gran oposición hubo entre los bancos comerciales a convertirse en asociados. Para adquirir esa categoría debían comprar acciones de la serie $\mathrm{B}$ del instituto central en una cantidad proporcional a su propio capital. Pero además del costo que implicaba esa asociación, la razón principal para negarse a asociarse era que, supuestamente, el Banco de México les hacía a los bancos comerciales una competencia desleal y ventajosa en razón de que por ley era el banco del gobierno federal. En consecuencia, al ser muy reducido el número de bancos que se asociaron al Banco de México, y al solicitar estos un volumen muy reducido de redescuento, la posibilidad que tuvo el billete para entrar por esa vía a la circulación fue en realidad reducida. Los datos registran que desde su apertura en septiembre de 1925 y hasta septiembre de 1931, el Banco de México había realizado operaciones de redescuento por la modesta suma de 12000000 de pesos. Y se dice modesta en razón de que la circulación monetaria total se estimaba entre 250000000 y 300000000 de pesos (Turrent, 1982, pp. 108-210).

Lo que sucedió a la postre es que, siendo muy reducida la emisión de billete, la cantidad de esa especie que logró permanecer en circulación 
fue mucho menor. Las cifras muestran que de septiembre de 1925 a junio de 1926 se habían ya emitido en billete casi 11000000 de pesos, aunque la cantidad máxima que se mantuvo en circulación nunca rebasó los 5000000 de pesos. En general, desde 1927 hasta 1931 el total de billetes emitidos se ubicó en poco más de 11000000 de pesos, mientras que los billetes en circulación languidecieron con tendencia a descender. De un máximo de 4800000 pesos que alcanzó ese registro en abril de 1926, el saldo empezó a descender hasta 1500000 en abril de 1927. En promedio, el saldo de billetes en circulación del cierre de 1925 al cierre de 1930 se ubicó en 2380467 pesos, descendiendo ese indicador a 791000 pesos en junio de 1931. En suma, mediante la emisión de billetes difícilmente podría haberse contrarrestado la contracción monetaria que se producía por la salida de oro del país y que tanto preocupó en su momento al ministro Montes de Oca.

\section{MÉXICO EN LA RECESIÓN MUNDIAL}

La coyuntura de la economía internacional, durante la que se intentó aplicar la reforma monetaria de 1931, fue particularmente desfavorable para los resultados que buscaban quienes formularon esa reforma. Lo que se buscaba era restablecer el tipo de cambio oficial de 2.006 pesos por dólar y resolver de paso el problema que había significado la depreciación de la moneda de plata respecto a la de oro. La expectativa de los responsables de esa reforma había sido que esas finalidades se consiguieran sin perturbaciones significativas al funcionamiento de la economía, sobre todo en su lado real: nivel de producción y empleo. Nada de lo anterior se consiguió. Lo que los perpetradores de esa reforma deseaban, ya se ha dicho, era que el esquema de patrón oro legalmente en vigor tuviera el comportamiento esperado. Es decir, que por efecto de la contracción monetaria el nivel de los precios se redujera mientras que los precios del exterior se mantuvieran relativamente estables. Esto último no ocurrió de la manera prevista, y de hecho lo que sucedió fue radicalmente opuesto a lo planteado. El nivel de precios del exterior se cayó incluso en mayor proporción que el nivel interno, impidiendo que se mejoraran los términos de intercambio para México. ¿Por qué?

En su libro El mundo en recesión, el distinguido historiador Charles Kindleberger (1986) da cuenta de cómo en el intervalo 1929-1931 la economía mundial cayó en la crisis más profunda de que se tenga memoria. Kindleberger reporta la severa caída que sufrieron, al menos de mediados de 1929 a principios de 1930, los precios mundiales de los principales productos primarios. En promedio, los precios de trece de esos bienes ca- 
yeron casi 40\% (cacao, café, cobre, maíz, algodón, pieles, plomo, caucho, seda, azúcar, estaño, trigo y zinc), mientras que las cotizaciones de café, algodón y caucho sufrieron las reducciones por encima de 50\%. Para Estados Unidos, de 1929 a 1932 el índice general de precios se desplomó de 179 a $131(26.3 \%)$ y el índice correspondiente a precios de mayoreo hasta 23\% (Kindleberger, 1986). En ese panorama de recesión desconsolador, un factor particularmente perjudicial fue la política monetaria contraccionista que aplicaron los bancos centrales de países industrializados. Nociva en especial en esta línea de actividad fue la política restrictiva que se siguió en Estados Unidos y en Gran Bretaña por el Sistema de Reserva Federal y el Banco de Inglaterra. En la posteridad, el juicio crítico ha sido severo respecto al sesgo procíclico que tomó la actuación de la Reserva Federal a lo largo de la recesión, pero en particular en los años de crisis más aguda: 1930 y 1931.

Ningún analista de respeto ha disputado que la política monetaria aplicada por la Reserva Federal de 1929 a 1933 fue altamente inadecuada y de consecuencias muy dañinas. El juicio al respecto de Milton Friedman y Ana Schwartz (1963) es que se trató de una política "inepta". La actuación de la Reserva Federal en esa coyuntura fue desfavorable no sólo por un comportamiento procíclico de la oferta monetaria respecto a la contracción de la actividad económica, sino también en razón de su pasividad para suministrar la liquidez que se requería urgentemente en un contexto en el que un número muy grande de bancos sufría retiros masivos. Para Friedman y Schwartz es un misterio el porqué el saldo de la cartera de bonos gubernamentales de la Reserva Federal se redujo y se mantuvo constante de 1929 a 1933 en lugar de crecer como lo aconsejaba la experiencia y la lógica bancaria (1963, pp. 407-411).

En Gran Bretaña la política monetaria restrictiva se derivó de la reimplantación del patrón oro, en 1925, al mismo tipo del cambio nominal que había tenido la libra cuando se abandonó ese esquema en 1914 a raíz del inicio de la primera guerra mundial. En términos reales ese tipo de cambio implicó una apreciación muy importante para la moneda británica, y su defensa requirió de contracción monetaria durante varios años, concretamente de 1925 a septiembre de 1931, en que el gobierno británico decidió abandonar en definitiva el patrón oro y el tipo de cambio de la libra buscó una cotización más acorde con la ley de la oferta y la demanda.

En suma, al igual que ocurrió en México durante la gestión de Luis Montes de Oca como ministro de Hacienda, también en Estados Unidos y en Gran Bretaña se siguió una política monetaria restrictiva. Las razones para esa forma de proceder fueron semejantes en esos países a las que se invocaron en México: intentar la defensa de un tipo de cambio oficial que se consideraba intocable e inamovible. Tampoco les ayudó en esa coyun- 
tura a los economistas ingleses y estadunidenses la teoría económica en vigor que tenían como paradigmas aceptados, la llamada Ley de Say y la ortodoxia del patrón oro.

\section{REFORMA MONETARIA FALLIDA Y CRITICADA}

Como se ha visto, los problemas que afectaban al sistema monetario de México estaban perfectamente identificados desde la época en que Plutarco Elías Calles tomó posesión como presidente en diciembre de 1924. Años más adelante, esos problemas y los efectos que tenían sobre la vida cotidiana de los mexicanos despertaron gran preocupación en el ministro Montes de Oca y también entre los integrantes del Consejo de Administración del Banco de México. Sin embargo, Anaya Merchant no hace alusión explícita a nada de esas realidades en su pomposo y estéril ensayo crítico sobre el tema. Más adelante, lo que llevó a Montes de Oca a actuar fue la intensificación que a lo largo de 1930 mostró tanto la depreciación de la moneda de plata contra la de oro como de ambas especies, pero en especial la de oro respecto al dólar de Estados Unidos. En consecuencia, de la intención de dar solución a esos dos problemas surgió la reforma monetaria de 1931.

Para llevar a cabo esa reforma, Montes de Oca convocó la colaboración de Manuel Gómez Morin y de otro técnico de nombre Luciano Wiechers. En el orden político logró también conseguir el apoyo de quien entonces mandaba en el país y era conocido como jefe máximo de la revolución. Por esta última razón, esa reforma fue publicitada políticamente como Plan Calles y, al entrar la iniciativa correspondiente a la consideración del Congreso, fue aprobada de manera servil, obsecuente y celebrada cínicamente por los legisladores con un absurdo grito: "iMuera el oro, viva la plata!" Así, siendo el ministro Montes de Oca el principal promotor histórico de esa ley deflacionista, la responsabilidad por la confección del proyecto no le fue exclusiva. En particular, en esa reforma monetaria de 1931 se escribió el capítulo más triste de Gómez Morin como reformador y joven proyectista al servicio de los generales sonorenses que llegaron a gobernar México en nombre de la revolución. Con todo, hay una débil luz de atenuación y de disculpa en favor de Montes de Oca y de sus compañeros de jornada: la doctrina y la teoría económica vigentes no los ayudaron en la concepción e implantación de su reforma monetaria y sí todo lo contrario.

En la exposición de motivos de la comentada ley se explica que ante la problemática monetaria que sufría México se abrieron a las autoridades tres posibles caminos a seguir: a) la restauración plena del patrón oro, $b$ ) 
la adopción del patrón plata o c) introducir ciertas modificaciones en el esquema monetario que hicieran posible su salvación.

En cuanto a la primera de las opciones enunciadas, la restauración plena del patrón oro hubiera sido imposible en términos presupuestales. Esa opción habría requerido de un caudal de al menos 200000000 de pesos, cantidad imposible de conseguir para el gobierno de Ortiz Rubio, atrapado por una severa recesión económica y, además, sin acceso al crédito internacional. Ese era el monto que hubiera sido necesario para recoger de la circulación la moneda de plata redundante que había sido creada en el lapso de 1920 a 1926 y que ascendía en términos gruesos a 150000000 de pesos. El remanente de 50000000 habría sido necesario para darle respaldo y canje al resto de la moneda de plata en circulación, la cual, como se ha visto, sumaba hacia 1927 aproximadamente 58000000 de pesos.

La adopción del patrón plata era una alternativa que aquellos reformadores tuvieron seguramente descartada de antemano. En contra de su aplicación estaba la muy desfavorable experiencia monetaria que había tenido México de 1873 a 1905, cuando el país se vio obligado a vivir con dicho esquema monetario. Teniéndose a la vista el muy importante y comprobado fenómeno de la volatilidad del precio de la plata respecto al oro, el tipo de cambio de la moneda mexicana habría seguido ese mismo curso de volatilidad. Ello, en razón de que los principales socios comerciales y financieros de México -esencialmente Estados Unidos, Gran Bretaña y Francia- tenían un régimen de patrón oro. Así, el tipo de cambio del peso mexicano fluctuaría en función de su contenido de plata y del precio de ese metal en el mercado internacional.

Quedó así disponible como única opción viable la tercera mencionada. ¿En qué consistió "la introducción de algunas reformas esenciales en el sistema legal"? Primero y principalmente, en la desmonetización de la moneda de oro. Con ello, las monedas acuñadas en ese metal y en manos del público se convirtieron en una simple mercancía que podía exportarse sin restricciones particulares. Con esa medida se daba al problema de la depreciación de la moneda de plata una solución que podría considerarse pírrica: simplemente ya no habría en la circulación y en el sistema la especie monetaria alternativa contra la cual pudieran desvalorarse las monedas de plata. Por su parte, la solución a la devaluación de la moneda mexicana respecto a las monedas del exterior consistiría en restaurar la paridad oficial de 1905 expresada en la equivalencia de 75 centigramos de oro puro por peso o 2.006 pesos por dólar.

El procedimiento funcional por el cual se conseguiría supuestamente esa revaluación sería la deflación monetaria. La secuencia causal sería, primero, que la reducción de la oferta monetaria por efecto de la desmonetización del oro produciría una disminución del nivel interno de precios; 
en una segunda fase, la caída del nivel interno de precios mejoraría los términos de intercambio del país, bajando los precios de las exportaciones y elevando los de las importaciones; más adelante, por último, este fenómeno de fortalecimiento de la competitividad internacional del país corregiría la balanza de pagos induciendo un equilibrio que terminaría en el restablecimiento de la paridad oficial del tipo de cambio.

Como es bien sabido, las cosas no ocurrieron en la forma prevista por aquellos legisladores monetarios. ¿Qué sucedió y cuál fue la secuencia de los hechos? Se materializaron las dos primeras fases. La desmonetización del oro dio lugar a una contracción de la masa monetaria a aproximadamente su mitad y la disminución de la masa monetaria provocó deflación, bajaron los precios internos de manera importante. Sin embargo, la deflación monetaria no indujo un fortalecimiento del tipo de cambio, sino todo lo contrario. Mientras que de enero a junio de 1931 el tipo de cambio de la moneda de oro respecto al dólar se ubicó en promedio en 2.10 pesos por dólar, de agosto de 1931 a febrero de 1932, durante la vigencia de la ley monetaria de 1931, esa cotización mostró el promedio de 2.78 pesos por dólar.

Una razón posible por la cual la deflación interna no logró incidir sobre el tipo de cambio fue que si los precios internos descendieron también lo hicieron, y quizá en mucho mayor medida, los precios del exterior. Un índice de precios de las exportaciones de México que calculaba el Banco Nacional de Fomento Industrial descendió casi 20\% de 1926 a 1931, al pasar su nivel de 112.37 a 89.96. Es decir, la deflación interna no tuvo como consecuencia el fortalecimiento de los términos de intercambio de México, medidos como la modificación del cociente entre los precios de las exportaciones y los de las importaciones.

\section{CONSECUENCIAS Y DOCTRINA}

En una visión de largo plazo, la reforma monetaria de 1931 tuvo el mérito, quizá casual, de que por esa vía se dio un paso importante en la transición de México a un régimen monetario completamente moderno basado en la moneda fiduciaria. Ese paso consistió en acabar para siempre con el patrón oro clásico y, como ya se ha dicho, implantar en México un esquema de talón de cambio (oro). Como todo patrón monetario, este último presentaba una regla cambiaria y una regla monetaria como elementos constitutivos. La regla cambiaria era un tipo de cambio fijo, aunque a diferencia con el régimen de talón oro, sería una cotización modificable en casos de necesidad extrema. La regla monetaria consistía en un sistema de circulación interna enteramente fiduciario o semifiduciario, cuyo funcionamiento 
requería de un banco central que tuviese a su cargo la tarea de poner dinero en circulación y administrar la cantidad de moneda en la economía.

En teoría, o en las intenciones de sus creadores, la ley monetaria de 1931 no debería haber sido tan deflacionista como resultó a final de cuentas. Ello porque a pesar de la contracción de la oferta monetaria por efecto de la desmonetización del oro, el esquema contemplaba una vía para la expansión circulatoria mediante la emisión de billetes por parte del Banco de México. Esta emisión se lograría por las operaciones de redescuento que se esperaba que los bancos comerciales solicitaran al Banco de México. Para tal fin se confiaba en que las operaciones de esa naturaleza se multiplicarían "cuando la situación lo permita por haberse logrado mantener prácticamente la paridad monetaria legal, cambio de oro o divisas extranjeras, a razón de 75 centigramos de oro puro" (Pani, 1950, p. 143). Pero en realidad, el desiderátum de que con la reforma monetaria de 1931 se iniciaría una emisión masiva de billetes parece utopía.

Que se lograra esa finalidad no sólo requería que se venciera en poco tiempo la repugnancia que había mostrado la población por ese medio circulatorio, sino también que los bancos comerciales, antagónicos al Banco de México desde su fundación, cambiaran de actitud y decidieran operar con esa institución. Finalmente, para ese desiderátum habría tenido que cumplirse con un requisito adicional aún más exigente, que se restableciera la paridad oficial de 1905, porque el billete sólo podría emitirse legalmente a la cotización de 2.006 pesos por dólar.

Los promotores de la ley monetaria de 1931 tuvieron una oportunidad de corregir el rumbo y, por tanto, de redimirse históricamente. En septiembre de 1931 y después de un intento costoso e impugnado por reimplantar el patrón oro, en Gran Bretaña se decidió desligar a la libra del metal amarillo. A mayor abundamiento, dicho curso de acción fue seguido por la mayoría de los países que se ubicaban en la zona esterlina. Es decir, emulando el ejemplo británico, los países de su zona monetaria también abandonaron el patrón oro y permitieron que sus monedas se devaluaran al impulso de la oferta y la demanda.

Pero tan trascendental suceso europeo no provocó reacción alguna en México. Aunque el país creador y promotor del patrón oro -con su culto a un tipo de cambio superfijo- había renunciado a dicha ortodoxia, en México se perseveró, con un celo digno de mejor causa, en el restablecimiento de la paridad histórica de 1905. Así ocurrió hasta que el país, la sociedad y la economía local no pudieron aguantar más. La consecuencia fue la renuncia de Montes de Oca como secretario de Hacienda en febrero de 1932, sumido en el oprobio y en el fracaso.

¿Por qué la obsesión de ese ministro y de sus asesores con la restauración de la paridad de 1905? No es fácil dar respuesta a esa pregunta. Una 
guía muy útil es que el pensamiento económico y la doctrina monetaria entonces en vigor no les resultaron de ayuda y de hecho fue contrario a lo ocurrido. En particular fueron dos paradigmas que llevaron a Montes de Oca y a sus colaboradores a la obnubilación del intelecto. El primero, la ortodoxia en que se fundaba el patrón oro, con la arraigada creencia de que un tipo de cambio era inamovible e inmodificable. Esa obsesión doctrinal -no se le puede llamar de otra forma- llevó a Montes de Oca, a Gómez Morin y a Wiechers a la confusión entre dos cosas que en realidad eran diferentes: una paridad y un régimen cambiario. Pragmático, intuitivo y sin esas ataduras doctrinales, el sucesor de Montes de Oca en la Secretaría de Hacienda, Alberto Pani, pudo ver la distinción enunciada con toda claridad y además la puso en práctica. Lo hizo conservando el régimen de patrón de cambio oro que se había implantado mediante la ley monetaria de 1931, pero permitiendo que el tipo de cambio se ubicara en una cotización viable y compatible con su mantenimiento. Así, de la aplicación de ese enfoque derivó el origen de la nueva paridad de 3.60 pesos por dólar que se alcanzó a partir de diciembre de 1933 y que se anunció como oficial en mayo de 1934.

El otro paradigma doctrinal que esclavizó el intelecto de los autores de la ley monetaria de 1931 fue la llamada Ley de Say. Es decir, la tesis de que existían fuerzas en la economía que en forma natural llevaban al sistema al equilibrio en una situación de pleno empleo. Así, en caso de que coyunturalmente la economía no se encontrara en esa situación, ya regresaría a ella de manera espontánea. Según ese enfoque, el alejamiento coyuntural de ese estado de equilibrio sólo podía explicarse por perturbaciones transitorias. La contrapartida monetaria de ese paradigma era la hipótesis sobre la neutralidad del dinero. Existía así, según esa teoría, una dicotomía inexorable. Por un lado, la cantidad de dinero incidía y determinaba únicamente el nivel de precios. Por otro, la actividad económica se determinaba únicamente en el lado real de la economía y tendía siempre al pleno empleo. Sin ser un teórico ni un pensador, Pani intuyó con claridad que en la vida práctica no existía tal dicotomía entre lo monetario y lo real. Tanto así que en México la contracción de la oferta a que había dado lugar la reforma monetaria de 1931 no sólo había inducido una reducción del nivel de los precios, sino también una intensa contracción de la actividad económica y del empleo.

En términos estrictamente teóricos, la dicotomía entre lo real y lo monetario y la Ley de Say no quedarían totalmente descartadas hasta algunos años después de la gran recesión de 1929-1931. La refutación llegó merced a la aparición del libro del economista inglés John Maynard Keynes (1936), La teoría general del empleo, el interés y el dinero. Sin embargo, en un orden intuitivo es claro que en México Pani fue un precursor de la llamada 
revolución keynesiana. No lo fue en el orden doctrinal porque Pani nunca fue un teórico. Pero sí lo fue en un sentido intuitivo, práctico y operativo.

El ministro mexicano observó que la restricción monetaria reprimía la actividad económica. Así, un medio eficaz para estimular la reactivación de la actividad económica sería la expansión monetaria. Por ello, al regresar a la Secretaría de Hacienda en febrero de 1932 puso a trabajar a todo vapor la fábrica de moneda para reponer con piezas de plata de nueva acuñación la moneda de oro que había quedado desmonetizada. Las estadísticas revelan que en 1932 y en el siguiente año se troqueló y emitió un total de 96000000 de pesos en monedas de plata.

\section{CONCLUSIONES}

Todo el cuidadoso trabajo de investigación y redacción incorporado en el trabajo de Luis Anaya Merchant desembocó en la esterilidad por una simple razón. Nunca logró enunciar (y probablemente entender) la problemática monetaria que llevó a la reforma monetaria de 1931. El tema no ha quedado desde luego agotado. En la agenda de pendientes de investigación sobre tan interesante suceso falta dilucidar la paternidad personal de las características específicas de la ley monetaria de 1931 entre sus ponentes Montes de Oca, Gómez Morin y Wiechers. Es también necesario explorar en qué medida contribuyó al fracaso de esa reforma el hecho de que se haya puesto en ejecución cuando el mundo atravesaba por lo más álgido de la recesión económica que atacó en esa época otro fenómeno dejado de lado hasta ahora por los investigadores: la influencia que tuvieron las fugas de capital en la intensa devaluación cambiaria que sufrió México al menos desde 1929 .

Desde cierta perspectiva simplista, el único error cometido por Montes de Oca y sus compañeros reformadores parece haber sido la obsesión por restaurar contra viento y marea la paridad oficial de 1905. En contrapartida, el único acierto de Pani parecería haber sido permitir que el tipo de cambio buscara un nivel compatible con su estabilización. Las cosas en la realidad no fueron tan sencillas. Además del pragmatismo, Pani tuvo a su favor una coyuntura internacional mucho más favorable que su antecesor. También se benefició de un ambiente político interno más propicio, cuando ya Ortiz Rubio había renunciado y empezó la presidencia, que a la postre resultó funcional, de Abelardo L. Rodríguez. En ese entorno menos antagónico, Pani tuvo el acierto de revertir la contracción monetaria, reponiendo con moneda de plata, de nueva creación, la moneda de oro que había quedado desmonetizada. Es dudoso que, de haber permanecido en la Secretaría de Hacienda, Montes de Oca hubiera reaccionado en esa 
misma forma pragmática. Ello, dada la repugnancia que siempre le habían despertado las acuñaciones de plata.

¿Qué habría pasado si Montes de Oca hubiera propuesto una reforma monetaria con desmonetización de la moneda de oro y búsqueda de una nueva paridad con una cotización más compatible con las circunstancias que prevalecían en el mercado de cambios? Desde luego, los resultados habrían sido mucho menos dañinos de lo que fueron a la postre. Con todo, en su arsenal de medidas habrían quizá faltado otros cambios indispensables que Pani acordó con facilidad y que no estaban disponibles en el horizonte intelectual de Montes de Oca. Por ejemplo, disponer que de manera definitiva el Banco de México dejara de tener facultades para operar como banco comercial y, a su vez, obligar a los bancos privados a asociarse al instituto central.

Finalmente, hay que explorar con mayor cuidado y profundidad lo que se ha hecho hasta ahora, cómo fue que Pani logró que entrara en circulación el billete del Banco de México. Montes de Oca observó que ese logro requería de un tipo de cambio fijo sostenible y creíble. Sin embargo, esa era tan sólo la condición necesaria para que el billete penetrara, faltaba que también se satisficieran las condiciones suficientes. Y es claro que, a priori, Pani no sabía cuáles eran estas y de qué forma podrían cumplirse. Así, la buena fortuna o el azar jugaron en su favor durante esa coyuntura difícil y transitoria. Un catalizador fueron las compras de moneda extranjera que empezó a hacer el Banco de México para conformar una reserva internacional suficiente y las cuales se liquidaban con billetes. Otro más -impensado para todos- fue que el vacío monetario dejado por las monedas desmonetizadas de oro únicamente podría ser llenado por dos especies: por monedas extranjeras, es decir, por divisas, o por billetes del Banco de México. El destino quiso que fuera esta última la solución al problema.

Reporta Anaya, en el ensayo en que hace alusión al Congreso de Economistas de enero de 1931, que en ese foro se hicieron muchas presentaciones sobre la problemática monetaria que padecía México hacia principios de la década de los treinta. El llamado es claro y conlleva una invitación: ¿̇en qué medida, en las sesiones de ese foro, se hicieron propuestas que apuntaban en la dirección de las soluciones que primeramente discurrió Pani antes de regresar a la Secretaría de Hacienda y que puso en ejecución una vez reinstalado a la cabeza de esa entidad? ¿Y si hubo esas propuestas, quiénes las formularon y por qué no fueron escuchadas en el orden intelectual y atendidas con un sentido práctico? Espero que las reflexiones contenidas en este ensayo contribuyan a profundizar y a mejorar la comprensión sobre la tan impugnada y cuestionada reforma monetaria de 1931. Ciertamente, tanto en los órdenes político y social como en mate- 
ria de historia económica es necesario mejorar la calidad del debate. Hay que tender puentes para un dialogo informado y sereno, aunque inexorablemente dialéctico. Eso espero de todo corazón.

\section{LISTA DE REFERENCIAS}

BetT, V. (1957). Central banking in México: Monetary policies and financial crises, 18641940. Ann Arbor: University of Michigan.

EspinosA, A. (16 de febrero de 1931). La depreciación monetaria actual. El Economista. FERNÁNDEZ, E. (comp.) (1976). Cincuenta años de banca central, ensayos conmemorativos 1925-1975. México: Banco de México/Fondo de Cultura Económica.

Friedman, M. y Schwartz, A. J. (1963). A monetary history of the United States, 18671960. Princeton: Princeton University Press.

GurZA, J. (1941). Las funciones monetarias del Banco de México (mimeo).

Kemmerer, E. (1917). Sistema monetario de México, reformas propuestas. México: Palacio Nacional.

Kindleberger, CH. (1986). The world in depression, 1929-1939. Los Ángeles: University of California Press.

Ley Orgánica del Banco de México [28 de agosto, 1936] (1958). Exposición de motivos. En Secretaría de Hacienda y Crédito Público, Legislación sobre el Banco de México. México: Secretaría de Hacienda y Crédito Público

Manero, Antonio (1958). La reforma bancaria en la revolución constitucionalista. México: s. e.

Nueva Ley Monetaria (agosto de 1931). El Linotipista.

Ortiz, R. (1942). La moneda mexicana. México: América.

Pani, A. J. (1950). Apuntes autobiográficos (2 vols., 2a. ed.). México: Porrúa.

Pani, A. J. (1955). El problema supremo de México. Ensayo de crítica constructiva de la política financiera. México: Imprenta Manuel Casas.

Quintana, M. (1931). Los ensayos monetarios como consecuencia de la baja de la plata: México: Universidad Nacional Autónoma de México.

Secretaría de Hacienda y CRédito Público (1926). Ley de impuestos a la minería y sus reglamentos. México: Ed. Cultura.

Secretaría de Hacienda y Crédito Público (1933). La crisis económica en México y la nueva legislación sobre la moneda y el crédito (vols. I y II). México: Ed. Cultura.

Secretaría de Hacienda y Crédito Público (1957). Ley que crea el Banco de México (25 de agosto de 1925). En Legislación sobre el Banco de México. México: Secretaría de Hacienda y Crédito Público.

Secretaría de Hacienda y Crédito Público (1959). Decreto que modifica el régimen monetario (13 de noviembre de 1918). En. Legislación monetaria (pp. 673-677). México: Secretaría de Hacienda y Crédito Público.

Turrent, E. (1982). Historia del Banco de México (vol. I). México: s. e. 